\title{
Differences in empathic concern and perspective taking across 63 countries
}

\author{
William J. Chopik ${ }^{1}$, Ed O’Brien², and Sara H. Konrath ${ }^{3}$ \\ ${ }^{1}$ Michigan State University \\ ${ }^{2}$ University of Chicago \\ ${ }^{3}$ Indiana University
}

Word Count: 6,074 (main text)

\begin{abstract}
Author Note
William J. Chopik, Department of Psychology, Michigan State University, East Lansing, MI. Ed O’Brien, The University of Chicago Booth School of Business, Chicago, IL. Sara H. Konrath, Lilly Family School of Philanthropy, Indiana University, Indianapolis, IN. Sara Konrath was funded by the John Templeton Foundation (via the Psychology of Character from Wake Forest University, and Grants \#47993 and \#57942 directly from the sponsor). The first two authors were supported by a National Science Foundation Graduate Research Fellowship.

Correspondence concerning this manuscript should be addressed to William J. Chopik, Department of Psychology, Michigan State University, 316 Physics Rd., East Lansing, Michigan 48824. E-mail: chopikwi@msu.edu
\end{abstract}

This is the author's manuscript of the article published in final edited form as:

Chopik, W. J., O’Brien, E., \& Konrath, S. H. (2017). Differences in Empathic Concern and Perspective Taking Across 63 Countries. Journal of Cross-Cultural Psychology, 48(1), 23-38. https://doi.org/10.1177/0022022116673910 


\begin{abstract}
Cultural practices socialize people to relate to others in different ways. One critical way in which these interpersonal bonds are formed and maintained is via empathy, our emotional reactivity towards others' internal experiences. However, the extent to which individuals from different cultures vary in their dispositional empathy, and the correlates of these differences, are relatively unknown. Thus, the current study explored cultural variation in empathy, and how this variation is related to psychological characteristics and prosocial behavior across cultures. Evidence from an original sample of 104,365 adults across 63 countries reveals that higher-empathy countries also have higher levels of collectivism, agreeableness, conscientiousness, self-esteem, emotionality, subjective well-being, and prosocial behavior. These findings reveal that empathy is situated within a broader nomological network of other psychological characteristics, emotional expression and experiences, and prosocial behavior across cultures. The current study expands our understanding about how psychological characteristics vary across cultures and how these characteristics can manifest in broader national indicators of prosocial behavior.
\end{abstract}

\title{
Abstract word count: 160
}

Keywords: empathy, cultural differences, prosocial behavior, collectivism, personality, emotion 
Empathy is defined as the tendency to be psychologically in tune with others' feelings and perspectives (Decety \& Lamm, 2006, p. 1147). This definition captures the widely accepted observation that empathic sensitivities are multi-dimensional in nature (Davis, 1994), comprised of distinct emotional (tendencies to feel concern and compassion for others) and cognitive components (tendencies to imagine different viewpoints beyond one’s own).

Empathy is associated with a wide array of intrapersonal and interpersonal outcomes (Konrath \& Grynberg, 2013). For example, empathy is positively related to life satisfaction, emotional intelligence, and self-esteem (Eisenberg, Fabes, \& Spinrad, 2006; Mayer, Caruso, \& Salovey, 2000; Richardson, Hammock, Smith, Gardner, \& Signo, 1994). More empathic people not only have larger and more fulfilling social networks compared to less empathic people, but they are also more prosocial: they volunteer more, donate more to charity, and are more likely help others in need, for more altruistic reasons (Davis, 1983; Grühn, Rebucal, Diehl, Lumley, \& Labouvie-Vief, 2008; Konrath, Ho, \& Zarins, 2016). Empathy is also sometimes understood as a type of competence or an attitude toward accounting for the feelings in other people (Singh \& Dali, 2013). Some evidence shows that interventions can increase this type of competency in people (Castillo, Salguero, Fernández-Berrocal, \& Balluerka, 2013; Konrath et al., 2015). However, dispositional empathy_-in terms of both its emotional and cognitive dimensions_-is generally considered an enduring individual characteristic that is relatively stable over time and across the lifespan (Eisenberg et al., 1999; Grühn et al., 2008).

To date, empathy has been primarily studied among North Americans, and as such, associations between empathy and both psychological characteristics (e.g., personality traits) and prosocial behavior (e.g., helping strangers, volunteering) have not been widely examined across different cultures. The relative lack of empirical focus on how empathy varies cross-culturally 
may be particularly important considering that cultures socialize us to relate to other people in different ways (Markus \& Kitayama, 1991), potentially affecting how empathy is experienced and expressed. In this study, we sought to address this gap by examining how country-level empathy (i.e., aggregated empathy scores of a country’s citizens) is related to country-level psychological characteristics and prosociality. We use data provided by other cross-cultural studies to situate our sample within a broader nomological network of psychological characteristics and prosocial behaviors.

\section{Empathy, Interdependence, and Culture}

Although scholars have examined empathy-related differences across cultures (e.g., in emotion recognition and expression; see Haidt \& Keltner, 1999; Soto \& Levenson, 2009), the vast majority of research into trait empathy focuses on people of Caucasian descent from North American countries (Konrath, O'Brien, \& Hsing, 2011; O'Brien, Konrath, Grühn, \& Hagen, 2013). Why might cultures vary on trait empathy? One major psychological difference across cultures is their individualism versus collectivism. Theoretically, empathy may be associated with the extent to which individuals construe themselves as an interdependent part of a larger social group. For example, the construct of sympathy (the acknowledgment of another person's feelings) is closely related to empathy (feeling care and concern for another person's feelings). Giving and receiving sympathy is theorized to be more closely tied to well-being within interdependent cultural contexts as compared to independent cultural contexts (Kitayama \& Markus, 2000). From this perspective, people from more individualistic cultures are thought to have a more individualized view of well-being, resulting from the actions of the individual agent. However, people from collectivistic cultures may be more likely to feel sympathy for others because their sense of well-being may be more intertwined with others. 
Yet, research that directly examines the relationship between empathy, culture, and culture-related variables like interdependence is rare, and often presents contradictory results. On the one hand, individual differences in interdependence are associated with increased tendencies to experience compassion and sympathy within both American and Japanese samples (Dalsky, Gohm, Noguchi, \& Shiomura, 2008). This would lead to the prediction that there may be higher levels of trait empathy in more collectivistic cultures compared to more individualistic cultures.

On the other hand, the few studies that have directly compared empathy-related processes across individualistic versus collectivistic countries reached the opposite conclusion. For example, Cassels and colleagues (2010) compared self-reported empathy scores in Western, East Asian, and Bicultural students. Western students reported higher empathy than Asian students, with Bicultural students falling in-between these two groups. One possible explanation provided by the researchers is that East Asian participants, because of their high levels of collectivism (or “interdependence”), perceive others’ emotions as more closely related to their own, particularly because the self and other are more closely integrated in the cultures. Thus, independence (versus interdependence) may facilitate the necessary psychological distance to be able to distinguish one’s own emotions from others' emotions, thus leading to higher Empathic Concern. Indeed, other studies find that US respondents reported higher mean-levels of empathy compared to Chinese respondents (Labouvie-Vief, Diehl, Tarnowski, \& Shen, 2000; Wu \& Keysar, 2007). These mean-level differences in empathy are consistent with an observational study of preschool children from four countries (i.e., Germany, Israel, Indonesia, Malaysia; Trommsdorff, Friedlmeier, \& Mayer, 2007). In this study, children witnessed an adult play partner experience a misfortune (having her balloon popped). Compared to children from Asian cultures (Indonesia and Malaysia), children from Western cultures (Germany and Israel) were more likely to offer 
partners their own balloon, give advice, and comfort or console the partner.

In sum, some research and theory suggests that trait empathy might be higher in collectivistic countries that value the interconnection between individuals. On the other hand, the few studies that directly compare countries suggest that trait empathy might be lower in collectivistic countries compared to individualistic countries. However, these studies are limited to comparisons among only two to four cultures at a time. The current study uses a much larger selection of countries to help address these conflicting research findings regarding the relationship between individualism-collectivism and empathy.

\section{Associations with Other Psychological Characteristics and Prosocial Behaviors}

The current study also explores how empathy relates to the most fundamental dimensions of personality. Besides situating empathy within a broader nomological network of psychological characteristics, another motivation for relating the empathy scores of participants in the current sample with psychological characteristics from other sources is to address the limitation that our survey was administered in English. If empathy is related to similar psychological constructs from previous examinations of cross-cultural differences in personality, especially those constructs from studies that used rigorous translation procedures and nationally representative samples, this provides some additional validity for our cross-cultural index of empathy. Finding consistent associations between empathy and psychological characteristics across cultures would strengthen the confidence of our findings by demonstrating convergent validity.

In samples of primarily North American college students, research finds that higher empathy is consistently associated with higher levels of agreeableness and conscientiousness. Agreeableness - the degree to which people are kind, gentle, and generous - is considered to be a primary interpersonal trait (Costa, McCrae, \& Dye, 1991). More agreeable people behave more 
prosocially, are less aggressive, and score higher on other-oriented traits such as compassion compared to less agreeable people (Graziano \& Eisenberg, 1997). It seems likely that agreeableness and trait empathy are related because they are both so closely linked to prosocial characteristics (Graziano, Habashi, Sheese, \& Tobin, 2007). Indeed, two of the sub-facets of agreeableness are “Tender-mindedness,” defined as attitudes of sympathy and concern for others (Costa \& McCrae, 1992) and “Altruism,” defined as a selflessness and concern for others. Both of these sub-facets are conceptually similar to empathy.

Conscientiousness — the tendency toward being reliable, organized, and dutiful—often translates into a better awareness of others and a greater consideration for others' needs (Aluja, García, \& García, 2002; John, Caspi, Robins, Moffitt, \& Stouthamer-Loeber, 1994). Given these research findings, we hypothesized that country-level empathy would be positively correlated with country-level agreeableness and conscientiousness, but would be unrelated to other dimensions of personality (extraversion, neuroticism, and openness to experience).

Another interesting question we address in this paper is the extent to which cross-cultural levels of empathy covary with cross-cultural levels of self-esteem. Although excessively high self-esteem may be detrimental to interpersonal relationships (see Bushman \& Baumeister, 1998), in general higher self-esteem enables people to care more about others because their own needs are taken care of and satisfied (Eisenberg et al., 2006). This idea is reflected in the robust positive correlation between self-esteem and engagement in prosocial and community activities (Larrieu \& Mussen, 1986; Yates \& Youniss, 1996). As such, we also hypothesized that countrylevel empathy would correlate with country-level self-esteem.

Empathy is also associated with how people feel about both their emotions and themselves. Individuals high in empathy tend to feel both their own and others' emotions more 
intensely than individuals low in empathy (Davis, 1983; Doherty, 1997; Eisenberg \& Miller, 1987; Konrath \& Grynberg, 2013). Thus, we hypothesized that trait empathy would be related to greater emotionality at the country level.

Moreover, studies have also linked higher levels of trait empathy to higher subjective well-being, and prosocial behavior is often hypothesized to help cultivate happiness (Tkach, 2006; Wei, Liao, Ku, \& Shaffer, 2011). This observation led to the hypothesis that trait empathy would be associated with higher subjective well-being at the country level.

In both academia and popular culture, empathy is perhaps most known for its link to prosocial behaviors. The most prototypic and commonly observed prosocial correlates of trait empathy are charitable donations, volunteerism, and helping (Davis, 1994; Eisenberg \& Miller, 1987; Hoffman, 2001). Based on this research, we also hypothesized that country-level empathy would be associated with country-level charitable donations, volunteerism, and helping behavior.

\section{The Current Study}

The current study examines cross-cultural variations in empathy. We address many of the limitations of prior work on cross-cultural differences in empathy that have led to contradictory findings. Previous investigations of cultural differences in empathy have been limited by both a small number of participants and cultural regions, examining, at most, four countries in a single study (Cassels et al., 2010; Trommsdorff et al., 2007). The current study thus examines crosscultural variation in empathy in a large Internet sample of 104,365 adults from 63 countries.

Our first goal was simply to document these differences across countries, providing the most comprehensive descriptive understanding of empathy around the world to date. Drawing on previous studies on regional variation in psychological characteristics (e.g., Rentfrow, Gosling, \& Potter, 2008; Schaller \& Murray, 2008; Schmitt et al., 2004), our second goal was to examine 
associations between these aggregate country-level empathy scores with country-level scores on collectivism, personality, self-esteem, emotionality, subjective well-being, and prosociality.

We formed our hypotheses under the assumption that individual-level associations between empathy and other constructs would generalize to the broader country-level, but we also acknowledge the problems of extending and assuming equivalence across these units of analysis (Ostroff, 1993; Robinson, 1950). Supplementary multi-level analyses in which culture-level variables predict individuals level responses yield similar results as those presented below. We hypothesized that country-level empathy would be positively related to country-level collectivism (though, given mixed evidence in past research, this hypothesis was somewhat exploratory); that empathy would be positively related to country-level agreeableness and conscientiousness, but unrelated to extraversion, neuroticism, and openness to experience; that empathy would be positively related to country-level self-esteem, emotionality, and subjective well-being; and finally, that empathy would be positively related to country-level indicators of prosocial behaviors, operationalized as charitable donations, volunteerism, and helping behavior.

\section{Method}

\section{Participants and Procedure}

Participants were 104,365 adults (61.2\% Male), ranging in age from 18 to 90 ( $M=36.83$, $S D=12.89$ ), who completed the survey online (via the third author's website). Participants received personalized feedback on their empathy scores at the end of the survey. Each participant responded to the question, "What is your country of residence?” The current sample includes participants from 63 countries, with the majority (74.3\%) residing within the United States (see Supplementary Tables 1 and 2 for breakdowns by cultural region and continental region). Given this overrepresentation of US participants, we used a procedure employed by Vandello \& Cohen 
(1999) to examine the relative influence of a particular region in studies of geographic comparisons and found that the associations reported below remain the same even when the United States was excluded from the analyses. An additional 555 participants (apart from the 104,365 adults) from 95 countries were excluded because there were fewer than 20 respondents per country in order to avoid problems associated with extremely small cell sizes.

Previous studies have shown that Internet-based samples can provide useful and valid data for psychological research (Chopik, Edelstein, \& Fraley, 2013; Srivastava, John, Gosling, \& Potter, 2003). Moreover, such samples are often more diverse than traditional undergraduate samples with respect to age, ethnicity, nationality, relationship status, and income (Gosling, Vazire, Srivastava, \& John, 2004). Participation was voluntary and participants received feedback on their empathy scores following completion. All participants completed the survey in English (a limitation that we address in the Discussion).

\section{Measures}

Empathy. Participants completed the Empathic Concern and Perspective Taking subscales of the Interpersonal Reactivity Index (Davis, 1983), a widely used measure of individual differences in empathy. The 7-item Empathic Concern subscale reflects a person’s other-oriented feelings of compassion for others, and as such represents an emotional component of empathy (e.g. "I often have tender, concerned feelings for people less fortunate than me”).

The 7-item Perspective Taking subscale reflects a person’s tendency to imagine others’ points of view, and as such represents a cognitive or intellectual component of empathy (e.g. "I sometimes try to understand my friends better by imagining how things look from their perspective”). Participants were asked to rate the extent to which they agreed with each item on a scale ranging from 1 (does not describe me well) to 5 (describes me very well), and the items were averaged to 
create subscales for Empathic Concern $(M=3.73, S D=.78 ; \alpha=.83)$ and Perspective Taking $(M$ $=3.64, S D=.75 ; \alpha=.82$ ). Empathic Concern and Perspective Taking were positively correlated, $r=.52, p<.001$, consistent with prior research (Davis, 1983). Because the two subscales were correlated, we also computed a simplified composite scale of Total Empathy $(M=3.68, S D=$ $.67 ; \alpha=.82)$, and included it in all the analyses below.

We tested the metric, scalar, residual, and structural invariance of the Interpersonal Reactivity Index by running a multi-group confirmatory factor analysis on six regions (North America, Europe, South America, Middle East, Oceania, and Asia). These results suggested invariance in factor loadings, item intercepts, item residuals, and factor variances. Complete details of these analyses are provided in Supplementary Tables 3-7.

We also tested whether differences in response styles (i.e., an acquiescence bias) between countries attenuated any of the results reported below. Following the recommended procedures (Harzing, 2006; van Herk, Poortinga, \& Verhallen, 2004), we calculated the proportion of items to which participants responded with 4 s and 5 s (on the 5-point scale; acquiescence) and the proportion of items to which participants responded with 1s and 2s (on the 5-point scale; disacquiescence). The average acquiescence balance (acquiescence minus disacquiescence) for each country was used as a measure of acquiescence bias. Entering this country-level measure of acquiescence bias as a covariate did not substantively change any of the results.

Hofstede’s dimensions. Hofstede and colleagues (2010) suggest that country-level differences in societal values can be characterized by five dimensions. Individualism/collectivism refers to the degree to which people prefer loosely knit social networks and individuality (higher values) versus tightly knit social networks and interdependence with others (lower values). Power Distance measures the degree to which a culture is accepting of inequality. 
Masculinity/Femininity assesses the degree to which a culture can be characterized by assertiveness and competitiveness (masculinity; higher values) or nurturance and cooperation (femininity; lower scores). Uncertainty Avoidance measures the degree to which a country’s citizens are uncomfortable with uncertainty and ambiguity. Long-Term Orientation assesses the outlook of a culture; countries with a long-term orientation place more importance on the future. Scores on each of these dimensions were gathered from Hofstede's latest reporting on cultural dimensions (Hofstede et al., 2010). Country-level scores on each of the dimensions were available for 59 countries in the current analyses. ${ }^{1}$

Big Five personality traits. Country-level scores on each of the Big Five personality traits were obtained from a large cross-cultural study of 17,837 individuals from 56 different cultures (Schmitt et al., 2007). Openness to Experience is the degree to which people are imaginative, creative, tolerant, and introspective (e.g., "I see myself as someone who has an active imagination.”; $\alpha=.76$ ). Conscientiousness is the tendency toward being reliable, organized, and dutiful (e.g., "I see myself as someone who does a thorough job.”; $\alpha=.78$ ). Extraversion is a tendency toward activity, assertiveness, and talkativeness (e.g., "I see myself as someone who is outgoing, sociable.”; $\alpha=$.77). Agreeableness is the degree to which people are kind, gentle, and generous (e.g., "I see myself as someone who is considerate and kind to almost everyone.”; $\alpha=$ .70). Neuroticism (versus Emotional Stability) is the degree to which people regularly experience negative affect such as irritability, depression, and anxiety (e.g., "I see myself as someone who can be tense.”; $\alpha=$.79). Participants in the previous cross-cultural study completed the Big Five Inventory (Benet-Martinez \& John, 1998), rating their agreement with 44 statements describing their personality on a scale ranging from 1 (disagree strongly) to 5 (agree strongly). Personality data was available for 42 countries in the current analyses. ${ }^{2}$ 
Self-Esteem. Country-level scores for self-esteem were obtained from the same study of cultural differences in Big Five traits. Self-esteem is defined as one’s sense of overall worthiness. The 10-item Rosenberg Self-Esteem Scale was completed by 16,998 individuals from 53 cultures ( = .81; Schmitt \& Allik, 2005). Participants were asked to rate the extent to which they agreed with each item on a scale ranging from 1 (strongly disagree) to 4 (strongly agree). A sample item is, "On the whole, I am satisfied with myself.” Self-esteem data was available for 41 countries in the current analyses.

Emotionality. Country-level percentages on the number of individuals reporting feeling each of ten emotional states, five positive (well-rested, being treated with respect, enjoyment, smiling and laughing a lot, and learning or doing something interesting) and five negative (anger, stress, sadness, physical pain, and worry) were used to measure emotionality. The Gallup World Poll defines this as a measure of emotionality within a country (Clifton, 2012).

Subjective well-being. Country-level scores on subjective well-being were taken from two separate sources. The first source is subjective well-being data on 59 countries taken from the Gallup World Poll using the Cantril Ladder of Life Scale (Cantril, 1965; Gallup, 2009; Helliwell, Layard, \& Sachs, 2013). Participants are instructed to respond with their current position on a ten-rung ladder ranging from 0 (the worst possible life for you) to 10 (the best possible life for you). The second source is subjective well-being data on 55 countries taken from the World Values Survey and is a composite measure of one item measuring happiness and one item measuring life satisfaction (see Inglehart, Foa, Peterson, \& Welzel, 2008). Happiness was measured with a single item, “Taking all things together, would you say you are...” Participants rated their happiness on a scale ranging from 1 (very happy) to 4 (not at all happy). Life satisfaction was measured with a single item, “All things considered, how satisfied are you with 
your life as a whole these days?” Participants responded to this item on a 10-point scale ranging from 1 (completely dissatisfied) to 10 (completely satisfied). Two sources of subjective wellbeing were included because there is a considerable debate about the methodology of measuring subjective well-being cross-culturally. Researchers warn against drawing conclusions based on comparisons using only one of these two data sets, because they are not directly comparable despite both purporting to measure subjective well-being across cultures (Bjørnskov, 2010).

Prosociality. Three measures of country-level prosocial behavior were taken from the World Giving Index, a Gallup-based survey of 153 countries around the world. A representative sample of 1,000 individuals over the age of 15 living in each country completed a questionnaire either via telephone or in a face-to-face interview. Participants indicated whether they had undertaken each of three charitable acts in the past month: (1) donated money to an organization, (2) volunteered time to an organization, and (3) helped a stranger or someone they didn’t know who needed help. Higher values indicate a higher percentage of the population who participated in each giving activity (charity, volunteerism, helping) in the past month. Data were available for all 63 countries in the current sample.

\section{Results}

\section{Preliminary Results}

Country-level means, standard deviations, rankings, and scale reliabilities for Empathic Concern, Perspective Taking, and Total Empathy are presented in Supplementary Table 1. The countries with the highest Total Empathy scores were Ecuador, Saudi Arabia, Peru, Denmark, and the United Arab Emirates. The countries with the lowest Total Empathy scores were Lithuania, Venezuela, Estonia, Poland, and Bulgaria. Consistent with prior research (Davis, 1983), women reported higher Empathic Concern $(M=4.05, S D=.65)$, Perspective Taking $(M=$ 
3.77, $S D=.70)$, and Total Empathy $(M=3.91, S D=.58)$ than men (Empathic Concern: $M=$ 3.53, $S D=.79$; Perspective Taking: $M=3.55, S D=.77$; Total Empathy: $M=3.54, S D=.68$ ), all ts $>$ 46.83, $p$ s $<.001, d s>.30$. Older individuals reported higher Empathic Concern $(r=.24, p<$ $.001)$, Perspective Taking $(r=.11, p<.001)$, and Total Empathy $(r=.20, p<.001)$ than younger individuals. This is also consistent with previous research on age differences in empathy (O'Brien et al., 2013). Psychological characteristics, cultural dimensions, and prosocial behavior were occasionally correlated with each other at modest levels (see Supplementary Table 9).

These preliminary results satisfy our first goal of documenting empathy scores across countries. Next, we turn to our second goal and report associations between country-level empathy and country-level collectivism, personality traits, self-esteem, emotionality, subjective well-being, and prosocial behaviors. Following the practice of previous research analyzing largescale cross-cultural data (Schmitt et al., 2004; Schmitt et al., 2007), we controlled for age and gender by calculating residualized country-level means for empathy.

\section{Is empathy associated with collectivism?}

To test how empathy was associated with individualism/collectivism and Hofstede’s other cultural dimensions, we regressed country-level individualism/collectivism scores onto country-level means for Empathic Concern, Perspective Taking, and Total Empathy separately, weighting for each country's sample size. The results of these analyses can be seen in the first panel of Table 1. Individualism/collectivism was negatively associated with Empathic Concern, such that more collectivistic countries had higher Empathic Concern. Individualism/collectivism was unrelated to Perspective Taking and marginally related to Total Empathy. None of the remaining Hofstede dimensions (Power Distance, Masculinity/Femininity, Uncertainty Avoidance, Long-term Orientation) were associated with Empathic Concern, Perspective Taking, 
or Total Empathy, all ps $>.29 .^{3}$

\section{Is empathy associated with agreeableness and conscientiousness?}

To test how empathy was associated with the big five personality traits across cultures, we regressed country-level means of each trait separately onto country-level means of each facet of empathy from our sample, while weighting for each country's sample size. The results of these analyses can be seen in the second panel of Table 1. As hypothesized, agreeableness and conscientiousness were consistently positively related to Empathic Concern, Perspective Taking, and Total Empathy across all cultures. As hypothesized, openness to experience and extraversion were only marginally related to Perspective Taking, and unrelated to Empathic Concern and Total Empathy. Neuroticism was also unrelated to empathy. Thus, we can conclude that empathy is related to psychological characteristics at the country level in a similar way as it is at the individual level.

\section{Is empathy associated with self-esteem, emotionality, and subjective well-being?}

We regressed country-level self-esteem, emotionality, and subjective well-being separately onto country-level means of empathy from our sample while weighting for each country's sample size. The results of these analyses can be seen in the second panel of Table 1. As hypothesized, self-esteem and emotionality were positively related to Empathic Concern, Perspective Taking, and Total Empathy across cultures. Also as hypothesized, life satisfaction was positively related to Empathic Concern, Perspective Taking, and Total Empathy across cultures using data from both the World Values Survey and the Gallup World Poll.

\section{Is empathy associated with prosocial behavior?}

To test whether empathy was related to prosocial behavior, we regressed country-level charitable donations, volunteerism, and helping separately onto country-level means for 
Empathic Concern, Perspective Taking, and Total Empathy, weighting for each country’s sample size. The results of these analyses can be seen in the third panel of Table 1. As hypothesized, volunteerism and helping were consistently positively related to Empathic Concern, Perspective Taking, and Total Empathy. Charitable giving was unrelated to any of the empathy scales, contrary to our hypotheses.

Because the national indices of prosocial behavior were intercorrelated $r s>.60$, ps $<$ .001 , we created a composite measure of prosocial acts by standardizing these three variables and averaging them $(\alpha=.83)$. This composite variable of prosocial acts was also positively associated with Empathic Concern, Perspective Taking, and Total Empathy.

\section{Discussion}

The current study represents the first large-scale examination of cross-country variation in dispositional empathy. Evidence from 63 countries reveals that collectivistic countries were higher in empathy compared to individualistic countries, and that country-level empathy was positively associated with country-level agreeableness, conscientiousness, self-esteem, emotionality, subjective well-being, and prosocial behaviors.

Many of these associations between empathy and personality, well-being, and prosocial behavior are consistent with previous samples consisting mostly of North American college students. To our knowledge, this study is by far the largest examination of cultural differences in empathy, with respect to both the number of individuals and the number of countries represented. We moved beyond comparing two cultures and examined how country-level empathy varied according to country-level collectivism. We also unified several disparate data sources of psychological characteristics and prosocial behavior to show the correlates of country-level empathy. These findings reveal that empathy is situated within a broader nomological network of 
other psychological characteristics, emotional expression and experiences, and prosocial behavior across cultures. The strong convergence of associations between country-level personality, emotionality, subjective well-being, and prosocial behavior with empathy allows us to characterize how interpersonal behavior varies across regions. Therefore, the current study significantly expands our understanding about how psychological characteristics vary across cultures and how these characteristics are reflected in national correlates of empathic responding. Below we focus on two findings in particular, given the large existing literatures on both topics: the cross-cultural association between empathy and collectivism, and between empathy and prosocial behaviors.

\section{Empathy, Culture, and Collectivism}

Previous research examining the association between collectivism and empathy has yielded inconsistent findings, with some research and theory suggesting a positive association between the two (e.g., Dalsky et al., 2008) and other research and theory suggesting a negative association between the two (e.g., Cassels et al., 2010). Markus and Kitayama (1991) suggest that other-focused emotions (e.g., compassion) are used to foster interdependence among individuals. Differences between individuals from individualistic and collectivistic cultures are hypothesized to originate from their early socialization environments. Parents from collectivistic cultures stress the strong interconnection of individuals (Lebra, 1976). For example, East Asian parents teach their children to fear loneliness and isolation, whereas Western parents generally focus on teaching children the benefits of being independent and unique. Children from collectivistic cultures also show more negative reactions to separation from their caregivers compared to children from individualistic cultures (Van Ijzendoorn \& Kroonenberg, 1988). Thus, the thoughts and feelings of people in interdependent contexts may be more closely tied to 
the thoughts and feelings of others around them (Markus \& Kitayama, 1991), which may account for their higher trait empathy compared to people in more independent contexts.

\section{Empathy, Culture, and Prosocial Behavior}

We also found that countries with higher levels of empathy reported higher levels of volunteerism and helping, but empathy was unrelated to charitable donations. There may be several reasons why empathy was not associated with charitable donations. Worth noting first is the considerable variability in how countries demonstrate prosocial behavior. Each country has its own unique way of acting prosocially. For example, in Liberia, only $8 \%$ of the population reported giving to a charity in the last month, one of the lowest percentages in the world. However, 76\% of the population reported helping a stranger in the last month, one of the highest percentages in the world. In this example, prosocial behavior is indeed high in Liberia, but not necessarily reflected in their charitable giving behavior. These differences in how prosocial behavior is expressed may also explain why, in some previous studies, certain types of helping behavior are generally higher in countries that report lower empathy in the current study (Johnson et al., 1989; Levine, Norenzayan, \& Philbrick, 2001).

Next, charitable donations may be more closely related to individuals’ personal wealth and resources rather than only their prosocial tendencies. Indeed, helping a stranger, which does not directly implicate an individual's wealth, was the most common prosocial act in the World Giving Index-nearly 45\% of the world's population reported helping a stranger in the last month. Future research can examine how country-level empathy is reflected in different expressions of country-level prosocial behavior, and whether there are other economic or social factors (e.g., Gross Domestic Product) that are associated with how empathy is expressed.

\section{Future directions}


Future research can examine the mechanisms that give rise to cross-cultural variability in empathy (Rentfrow, 2010; Rentfrow et al., 2008). For example, are individuals with a particular set of psychological characteristics (e.g., high Empathic Concern) more likely to move to certain areas (i.e., selective migration)? Or do the social/cultural characteristics of an area exert their influence on individuals to make them more empathic (i.e., social influence)? How long does an individual have to live in a particular culture before they assimilate (if ever; Heine \& Lehman, 2004)? Unfortunately, we only collected information on participants' country of residence and not on their country of origin or history of cross-cultural mobility. Future research can examine the conditions under which cultural differences in empathy emerge and how socialization pressures exert their influence on individuals over time (Oishi, 2010). Extant work on examining the origins of collectivism would be a useful avenue for future research in this regard (see Phalet \& Schönpflug, 2001; Schaller \& Murray, 2008; for a discussion on intergenerational transmission, evolutionary, and social learning perspectives on collectivism).

One major limitation of the current study is that the survey was administered in English to all participants, which may be problematic in studies of self-reported psychological characteristics. For example, when students are randomly assigned to complete a survey in English (compared to their native language), their scores tend to reflect English students’ psychological characteristics (Ross, Xun, \& Wilson, 2002). However, we believe there are at least three reasons our study provides useful information about cultural differences in empathy.

First, country-level empathy (assessed in English) was positively associated with country-level conscientiousness, agreeableness, self-esteem, emotionality, subjective well-being, and prosocial behavior (all assessed in the country's native language). Information about psychological characteristics and prosocial behaviors were taken from entirely different data 
sources initiated by researchers who implemented rigorous translation procedures. The fact that country-level empathy was related to psychological constructs and prosocial behavior from entirely different data sources in a priori hypothesized ways suggests that our index of empathy may indeed approximate country-level empathy. Further, our predictions were all derived from previous theory and research on empathy and replicate some of the associations found in individual-level data. For example, we replicated the effect that empathy is unrelated to neuroticism, extraversion, and openness to experience when assessed at the individual-level. These null effects are important to show that empathy in our sample is also unrelated to psychological characteristic in other samples in predictable ways.

Second, the limitation of participants completing a survey in English language would shift our samples to be more homogenous, thereby reducing the differences between individualistic and collectivistic cultures. If anything, the results of the current study may be an underestimate of actual variations in empathy across cultures. ${ }^{4}$

Third, internet surveys examining cross-cultural differences in psychological characteristics are generally representative and match the demographic make-up of the population, even when they are administered entirely in English (Brumbaugh \& Wood, 2013). Also, Internet surveys administered in English often replicate the results of surveys conducted in native languages (Chopik \& Edelstein, 2014). Unfortunately, our use of convenience samples leave us unable to determine if the empathy scores observed in the current study reflect the empathy scores from nationally representative samples from each country. The differences in empathy between our sample and the true national average may be most pronounced in those countries from which we had fewer participants.

Although these three points strengthen the confidence of our findings, future studies 
should nevertheless utilize rigorous translation procedures when comparing countries on psychological characteristics. Collecting larger, more representative samples with a comparable number of participants in each country completing native-language surveys will help to address problems with the current study. The complex associations between empathy, collectivism, and each of our outcomes highlight the need to carefully consider not only the sampling of individuals within a particular country but also the countries included in studies examining crosscultural differences in empathy and prosocial behavior. Inadequate sampling of countries could change the magnitude or signs of many associations given the large variation between countries in other domains (e.g., affluence). Examining additional correlates of country-level empathy (e.g., aggression, pride, affluence, other prosocial indicators) would also be informative, to the extent that potential data is of a comparable size and representation of countries as in our empathy data.

\section{Conclusion}

In the current study, we took an important step toward understanding how empathy varies across cultures. In a sample of 104,365 adults from 63 countries, countries with higher levels of empathy also had higher levels of collectivism, agreeableness, conscientiousness, self-esteem, emotionality, life satisfaction, and prosocial behavior. Despite the strong influence that culture has on how we relate to others around us (Markus \& Kitayama, 1991), researchers have generally relied on samples of North American college students when studying empathy. Given the important role of empathy in everyday social life, we hope that the current study will stimulate research examining how empathy is expressed in different cultures and social settings, and help inform future research on the relationship between empathy and culture from a broader and a more representative perspective. 
Table 1

Regressions predicting Empathic Concern, Perspective Taking, and Total Empathy from Psychological Variables, Hofstede’s Cultural

Dimensions, and Social Variables of Prosocial Acts

\begin{tabular}{|c|c|c|c|c|}
\hline & Empathic Concern & Perspective Taking & Total Empathy & $k$ \\
\hline \multicolumn{5}{|l|}{ Hofstede's Cultural Dimensions } \\
\hline Individualism/Collectivism & $-.33 * *$ & -.11 & $-.25^{\dagger}$ & 59 \\
\hline Power Distance & .08 & -.06 & .01 & 59 \\
\hline Masculinity/Femininity & .11 & -.03 & .05 & 59 \\
\hline Uncertainty Avoidance & .01 & .06 & .04 & 59 \\
\hline Long-Term Orientation & -.04 & -.08 & -.07 & 59 \\
\hline \multicolumn{5}{|l|}{ Psychological Variables } \\
\hline Openness to Experience & .13 & $.21^{\dagger}$ & .20 & 42 \\
\hline Conscientiousness & $.44^{* *}$ & $.48 * *$ & $.48^{* *}$ & 42 \\
\hline Extraversion & .17 & $.27^{\dagger}$ & .23 & 42 \\
\hline
\end{tabular}




\begin{tabular}{|c|c|c|c|c|}
\hline Agreeableness & $.35 *$ & $.44^{* *}$ & $.41^{* *}$ & 42 \\
\hline Neuroticism & -.08 & -.24 & -.16 & 42 \\
\hline Self-Esteem & $.42 * *$ & $.48 * *$ & $.47 * *$ & 41 \\
\hline Emotionality & $.41^{* *}$ & $.49 * *$ & $.47 * *$ & 59 \\
\hline Subjective Well-Being (WVS) & $.29 *$ & $.48 * *$ & $.40 * *$ & 55 \\
\hline Subjective Well-Being (Gallup) & $.21^{\dagger}$ & $.50 * *$ & $.37 * *$ & 59 \\
\hline \multicolumn{5}{|l|}{ osociality } \\
\hline Charitable Giving & .03 & .10 & .07 & 63 \\
\hline Volunteerism & $.31 *$ & $.42^{* *}$ & $.38^{* *}$ & 63 \\
\hline Helping & $.32 *$ & $.39 * *$ & $.37 * *$ & 63 \\
\hline Composite of Empathic Acts & $.26 *$ & $.36^{* *}$ & $.32 *$ & 63 \\
\hline
\end{tabular}

Note. ${ }^{\dagger} p<.10,{ }^{* *} p<.05,{ }^{* *} p<.01$ 


\section{References}

Aluja, A., García, Ó., \& García, L. F. (2002). A comparative study of Zuckerman's three structural models for personality through the NEO-PI-R, ZKPQ-III-R, EPQ-RS and Goldberg's 50-bipolar adjectives. Personality and Individual Differences, 33(5), 713-725.

Benet-Martinez, V., \& John, O. P. (1998). Los Cinco Grandes across cultures and ethnic groups: Multitrait-multimethod analyses of the Big Five in Spanish and English. Journal of Personality and Social Psychology, 75(3), 729-750.

Bjørnskov, C. (2010). How Comparable are the Gallup World Poll Life Satisfaction Data? Journal of Happiness Studies, 11(1), 41-60.

Brumbaugh, C. C., \& Wood, D. (2013). Mate preferences across life and across the world. Social Psychological and Personality Science, 4(1), 100-107.

Bushman, B. J., \& Baumeister, R. F. (1998). Threatened egotism, narcissism, self-esteem, and direct and displaced aggression: Does self-love or self-hate lead to violence? J Pers Soc Psychol, 75(1), 219-229.

Cantril, H. (1965). The pattern of human concerns. New Brunswich, NJ: Rutgers University Press.

Cassels, T. G., Chan, S., Chung, W., \& Birch, S. A. J. (2010). The role of culture in affective empathy: Cultural and bicultural differences. Journal of Cognition and Culture, 10(3-4), 309-326.

Castillo, R., Salguero, J. M., Fernández-Berrocal, P., \& Balluerka, N. (2013). Effects of an emotional intelligence intervention on aggression and empathy among adolescents. Journal of Adolescence, 36(5), 883-892.

Chopik, W. J., \& Edelstein, R. S. (2014). Age differences in romantic attachment around the 
world. Social Psychological and Personality Science, 5(8), 892-900.

Chopik, W. J., Edelstein, R. S., \& Fraley, R. C. (2013). From the cradle to the grave: Age differences in attachment from early adulthood to old age. Journal of Personality, 81(2), 171-183.

Clifton, J. (2012). Singapore ranks as least emotional country in the world. Gallup. Retrieved from http://www.gallup.com/poll/158882/singapore-ranks-least-emotional-country$\underline{\text { world.aspx }}$

Costa, P. T., \& McCrae, R. R. (1992). Revised NEO Personality Inventory (NEO PI-R) and NEO Five-Factor Inventory (NEOFFI): Professional manual.

Costa, P. T., McCrae, R. R., \& Dye, D. A. (1991). Facet scales for agreeableness and conscientiousness: A revision of the NEO Personality Inventory. Personality and Individual Differences, 12(9), 887-898.

Dalsky, D., Gohm, C. L., Noguchi, K., \& Shiomura, K. (2008). Mutual self-enhancement in Japan and the United States. Journal of Cross-Cultural Psychology, 39(2), 215-223.

Davis, M. H. (1983). Measuring individual differences in empathy: Evidence for a multidimensional approach. J Pers Soc Psychol, 44(1), 113-126.

Davis, M. H. (1994). Empathy: A social psychological approach. Boulder, CO: Westview Press.

Decety, J., \& Lamm, C. (2006). Human empathy through the lens of social neuroscience. The Scientific World Journal, 6, 1146-1163.

Doherty, R. W. (1997). The emotional contagion scale: A measure of individual differences. Journal of Nonverbal Behavior, 21(2), 131-154.

Eisenberg, N., Fabes, R. A., \& Spinrad, T. L. (2006). Prosocial Development. In N. Eisenberg, W. Damon, \& R. M. Lerner (Eds.), Handbook of child psychology: Vol. 3, Social, 
emotional, and personality development (6th ed.). (pp. 646-718). Hoboken, NJ: John Wiley \& Sons Inc.

Eisenberg, N., Guthrie, I. K., Murphy, B. C., Shepard, S. A., Cumberland, A., \& Carlo, G. (1999). Consistency and development of prosocial dispositions: a longitudinal study. Child Development, 70(6), 1360-1372.

Eisenberg, N., \& Miller, P. A. (1987). The relation of empathy to prosocial and related behaviors. Psychological Bulletin, 101(1), 91-119.

Gallup. (2009). World Poll Methodology. Retrieved from Washington, D. C.:

Gorodnichenko, Y., \& Roland, G. (2011). Individualism, innovation, and long-run growth. Proceedings of the National Academy of Sciences, 108(Supplement 4), 21316-21319.

Gosling, S. D., Vazire, S., Srivastava, S., \& John, O. P. (2004). Should we trust web-based studies? A comparative analysis of six preconceptions about internet questionnaires. American Psychologist, 59(2), 93-104.

Graziano, W. G., \& Eisenberg, N. (1997). Agreeableness: A dimension of personality. In R. Hogan, J. A. Johnson, \& S. R. Briggs (Eds.), Handbook of personality psychology. (pp. 795-824). San Diego, CA US: Academic Press.

Graziano, W. G., Habashi, M. M., Sheese, B. E., \& Tobin, R. M. (2007). Agreeableness, empathy, and helping: A person × situation perspective. J Pers Soc Psychol, 93(4), 583599.

Grühn, D., Rebucal, K., Diehl, M., Lumley, M., \& Labouvie-Vief, G. (2008). Empathy across the adult lifespan: Longitudinal and experience-sampling findings. Emotion, 8(6), 753765.

Haidt, J., \& Keltner, D. (1999). Culture and facial expression: Open-ended methods find more 
expressions and a gradient of recognition. Cognition and Emotion, 13(3), 225-266.

Harzing, A.-W. (2006). Response Styles in Cross-national Survey Research: A 26-country Study. International Journal of Cross Cultural Management, 6(2), 243-266.

He, J., van de Vijver, F. J. R., Dominguez Espinosa, A., Abubakar, A., Dimitrova, R., Adams, B. G., ... Villieux, A. (2015). Socially Desirable Responding: Enhancement and Denial in 20 Countries. Cross-Cultural Research, 49(3), 227-249.

Heine, S. J., \& Lehman, D. R. (2004). Move the body, change the self: Acculturative effects on the self-concept. In M. Schaller \& C. S. Crandall (Eds.), The psychological foundations of culture (pp. 305-331). Mahwah, NJ: Lawrence Erlbaum Associates, Inc.

Helliwell, J., F., Layard, R., \& Sachs, J. (2013). World Happiness Report 2013. New York, NY: UN Sustainable Development Solutions Network.

Hoffman, M. L. (2001). Toward a comprehensive empathy-based theory of prosocial moral development. In A. C. Bohart \& D. J. Stipek (Eds.), Constructive \& destructive behavior: Implications for family, school, \& society. (pp. 61-86). Washington, DC: American Psychological Association.

Hofstede, G. H., Hofstede, G. J., \& Minkov, M. (2010). Cultures and organizations: Software of the mind. New York, NY: McGraw-Hill.

Inglehart, R., Foa, R., Peterson, C., \& Welzel, C. (2008). Development, freedom, and rising happiness: A global perspective (1981-2007). Perspectives on Psychological Science, 3(4), 264-285.

John, O. P., Caspi, A., Robins, R. W., Moffitt, T. E., \& Stouthamer-Loeber, M. (1994). The 'little five': Exploring the nomological network of the five-factor model of personality in adolescent boys. Child Development, 65(1), 160-178. 
Johnson, R. C., Danko, G. P., Darvill, T. J., Bochner, S., Bowers, J. K., Huang, Y.-H., .. . Pennington, D. (1989). Cross-cultural assessment of altruism and its correlates. Personality and Individual Differences, 10(8), 855-868.

Kitayama, S., \& Markus, H. R. (2000). The pursuit of happiness and the realization of sympathy: Cultural patterns of self, social relations, and well-being. In E. Diener \& E. M. Suh (Eds.), Culture and subjective well-being. (pp. 113-161). Cambridge, MA: The MIT Press.

Konrath, S., Falk, E., Fuhrel-Forbis, A., Liu, M., Swain, J., Tolman, R., . . . Walton, M. (2015). Can text messages increase empathy and prosocial behavior? The development and initial validation of Text to Connect. PLoS ONE, 10(9), e0137585.

Konrath, S., \& Grynberg, D. (2013). The positive (and negative) psychology of empathy. In D. Watt \& J. Panksepp (Eds.), The neurobiology and psychology of empathy: Nova Science Publishers, Inc., In press.

Konrath, S., Ho, M.-H., \& Zarins, S. (2016). The strategic helper: Narcissism and prosocial motives and behaviors. Current Psychology, 35(2), 182-194.

Konrath, S., O'Brien, E., \& Hsing, C. (2011). Changes in dispositional empathy in American college students over time: a meta-analysis. Personality and Social Psychology Review, 15(2), 180-198.

Labouvie-Vief, G., Diehl, M., Tarnowski, A., \& Shen, J. (2000). Age differences in adult personality: Findings from the United States and China. The Journals of Gerontology: Series B: Psychological Sciences and Social Sciences, 55B(1), P4-P17.

Larrieu, J., \& Mussen, P. (1986). Some personality and motivational correlates of children's prosocial behavior. The Journal of Genetic Psychology: Research and Theory on Human 
Development, 147(4), 529-542.

Lebra, T. S. (1976). Japanese patterns of behavior. Honolulu, HI: University of Hawaii Press.

Levine, R. V., Norenzayan, A., \& Philbrick, K. (2001). Cross-cultural differences in helping strangers. Journal of Cross-Cultural Psychology, 32(5), 543-560.

Markus, H. R., \& Kitayama, S. (1991). Culture and the self: Implications for cognition, emotion, and motivation. Psychological Review, 98(2), 224-253.

Mayer, J. D., Caruso, D. R., \& Salovey, P. (2000). Selecting a measure of emotional intelligence: The case for ability scales. In R. Bar-On \& J. D. A. Parker (Eds.), The handbook of emotional intelligence: Theory, development, assessment, and application at home, school, and in the workplace. (pp. 320-342). San Francisco, CA: Jossey-Bass.

McCrae, R. R., \& Terracciano, A. (2005a). Personality profiles of cultures: Aggregate personality traits. J Pers Soc Psychol, 89(3), 407-425.

McCrae, R. R., \& Terracciano, A. (2005b). Universal features of personality traits from the observer's perspective: Data from 50 cultures. J Pers Soc Psychol, 88(3), 547-561.

O'Brien, E., Konrath, S. H., Grühn, D., \& Hagen, A. L. (2013). Empathic concern and perspective taking: Linear and quadratic effects of age across the adult life span. The Journals of Gerontology: Series B: Psychological Sciences and Social Sciences, 68B(2), 168-175.

Oishi, S. (2010). The psychology of residential mobility: Implications for the self, social relationships, and well-being. Perspectives on Psychological Science, 5(1), 5-21.

Ostroff, C. (1993). Comparing correlations based on individual-level and aggregated data. Journal of Applied Psychology, 78(4), 569.

Phalet, K., \& Schönpflug, U. (2001). Intergenerational Transmission of Collectivism and 
Achievement Values in Two Acculturation Contexts: The Case of Turkish Families in Germany and Turkish and Moroccan Families in the Netherlands. Journal of CrossCultural Psychology, 32(2), 186-201.

Rentfrow, P. J. (2010). Statewide differences in personality: Toward a psychological geography of the United States. American Psychologist, 65(6), 548-558.

Rentfrow, P. J., Gosling, S. D., \& Potter, J. (2008). A theory of the emergence, persistence, and expression of geographic variation in psychological characteristics. Perspectives on Psychological Science, 3(5), 339-369.

Richardson, D. R., Hammock, G. S., Smith, S. M., Gardner, W., \& Signo, M. (1994). Empathy as a cognitive inhibitor of interpersonal aggression. Aggressive Behavior, 20(4), 275-289.

Robinson, W. S. (1950). Ecological correlations and the behavior of individuals. American Sociological Review, 15, 351-357.

Ross, M., Xun, W. Q. E., \& Wilson, A. E. (2002). Language and the bicultural self. Personality and Social Psychology Bulletin, 28(8), 1040-1050.

Schaller, M., \& Murray, D. R. (2008). Pathogens, personality, and culture: Disease prevalence predicts worldwide variability in sociosexuality, extraversion, and openness to experience. J Pers Soc Psychol, 95(1), 212-221.

Schmitt, D. P., Alcalay, L., Allensworth, M., Allik, J., Ault, L., Austers, I., . . Scrimali, T. (2004). Patterns and universals of adult romantic attachment across 62 cultural regions: Are models of self and of other pancultural constructs? Journal of Cross-Cultural Psychology, 35(4), 367-402.

Schmitt, D. P., \& Allik, J. (2005). Simultaneous administration of the Rosenberg Self-Esteem Scale in 53 nations: Exploring the universal and culture-specific features of global self- 
esteem. J Pers Soc Psychol, 89(4), 623-642.

Schmitt, D. P., Allik, J., McCrae, R. R., Benet-Martínez, V., Alcalay, L., Ault, L., . . Boholst, F. (2007). The geographic distribution of Big Five personality traits: Patterns and profiles of human self-description across 56 nations. Journal of Cross-Cultural Psychology, 38(2), 173-212.

Schwartz, S. H. (2006). A theory of cultural value orientations: Explication and applications. Comparative Sociology, 5(2-3), 137-182.

Singh, P., \& Dali, C. M. (2013). The value of empathy as an instructional leadership competency for school principals. Education as Change, 17(sup1), S65-S78.

Soto, J. A., \& Levenson, R. W. (2009). Emotion recognition across cultures: The influence of ethnicity on empathic accuracy and physiological linkage. Emotion, 9(6), 874-884.

Srivastava, S., John, O. P., Gosling, S. D., \& Potter, J. (2003). Development of personality in early and middle adulthood: Set like plaster or persistent change? J Pers Soc Psychol, 84(5), 1041-1053.

Terracciano, A., Abdel-Khalek, A. M., Ádám, N., Adamovová, L., Ahn, C. k., Ahn, H. n., .. . McCrae, R. R. (2005). National character does not reflect mean personality trait levels in 49 cultures. Science, 310(5745), 96-100.

Tkach, C. T. (2006). Unlocking the treasury of human kindness: Enduring improvements in mood, happiness, and self-evaluations (Doctoral dissertation, University of California, Riverside, 2006). Dissertation Abstracts International, 67, 603.

Trommsdorff, G., Friedlmeier, W., \& Mayer, B. (2007). Sympathy, distress, and prosocial behavior of preschool children in four cultures. International Journal of Behavioral Development, 31(3), 284-293. 
UNDP. (2015). Human Development Report. New York, NY: Oxford University Press.

van Herk, H., Poortinga, Y. H., \& Verhallen, T. M. M. (2004). Response Styles in Rating Scales: Evidence of Method Bias in Data From Six EU Countries. Journal of Cross-Cultural Psychology, 35(3), 346-360.

Van Ijzendoorn, M. H., \& Kroonenberg, P. M. (1988). Cross-cultural patterns of attachment: A meta-analysis of the strange situation. Child Development, 59(1), 147-156.

Vandello, J. A., \& Cohen, D. (1999). Patterns of individualism and collectivism across the United States. J Pers Soc Psychol, 77(2), 279-292.

Voronov, M., \& Singer, J. A. (2002). The myth of individualism-collectivism: A critical review. The Journal of Social Psychology, 142(4), 461-480.

Wei, M., Liao, K. Y., Ku, T. Y., \& Shaffer, P. A. (2011). Attachment, self-compassion, empathy, and subjective well-being among college students and community adults. Journal of Personality, 79(1), 191-221.

Wu, S., \& Keysar, B. (2007). The effect of culture on perspective taking. Psychological Science, 18(7), 600-606.

Yates, M., \& Youniss, J. (1996). Community service and political-moral identity in adolescents. Journal of Research on Adolescence, 6(3), 271-284. 
${ }^{1}$ There are many dimensions on which countries vary. In the current study, we chose to focus on constructs that have been shown to be associated with empathy on the individual level. Nevertheless, in many studies comparing cultures (e.g., He et al., 2015), it is common to examine how psychological characteristics are related to indicators like Schwartz’s (2006) value orientations (intellectual autonomy, affective autonomy, embeddedness, egalitarianism, hierarchy, harmony, and mastery). In a series of supplementary analyses, we found that every indicators of country-level empathy were unrelated to country-level value orientations with one exception (Empathic Concern was associated with higher mastery). These analyses and a brief description of the value orientations examined can be found in Supplementary Table 8 (for regression-based analyses).

2 There are a number of studies that have examined cross-cultural differences in the Big Five (McCrae \& Terracciano, 2005a, 2005b; Schmitt et al., 2007; Terracciano et al., 2005). We elected to use the Schmitt scores because they provided the largest set of comparison countries that overlapped with the present report.

${ }^{3}$ One common critique with studying cultural dimensions is that many of these indices correlate highly with the development of a country (e.g., its standard of living, access to education, and life expectancy; Gorodnichenko \& Roland, 2011; Voronov \& Singer, 2002). In a supplementary analysis, we found that empathy was unrelated to the Human Development Index (UNDP, 2015), suggesting that empathy's associations with individualism/collectivism are not subsumed by considering the development of a country (see Supplementary Table 9).

${ }^{4}$ We also examined whether the empathy varied systematically with the percentage of a country’s population that spoke English. For example, respondents from a country in which a 
very small portion of population knows English may be psychologically different than respondents from a country in which knowing English is relatively common, possibly affecting their empathy scores. Reliable percentages of English speakers were available for 50 out of the 63 countries in the current study. The percentage of English speakers within each country was unrelated to Empathic Concern $(p=.54)$, Perspective Taking $(p=.29)$, and Total Empathy $(p=$ $.35)$. 
Supplementary Table 1

Sample Sizes and Descriptive Statistics

\begin{tabular}{|c|c|c|c|c|c|c|c|c|c|c|c|c|c|}
\hline \multirow[b]{3}{*}{ Cultural Regions } & \multirow{3}{*}{$\begin{array}{c}\underline{\text { Sample }} \\
\underline{\text { Size }} \\
\mathrm{n}\end{array}$} & \multicolumn{2}{|c|}{ Empathic } & \multirow{3}{*}{$\begin{array}{c}\underline{\mathrm{EC}} \\
\underline{\text { Rank }}\end{array}$} & \multirow{3}{*}{$\begin{array}{l}\underline{\mathrm{EC}} \\
\underline{\alpha}\end{array}$} & \multirow{2}{*}{\multicolumn{2}{|c|}{$\begin{array}{l}\text { Perspective Taking } \\
\text { (PT) }\end{array}$}} & \multirow{3}{*}{$\begin{array}{l}\underline{\mathrm{PT}} \\
\underline{\mathrm{Rank}}\end{array}$} & \multirow{3}{*}{$\begin{array}{l}\underline{\mathrm{PT}} \\
\underline{\alpha}\end{array}$} & \multirow{2}{*}{\multicolumn{2}{|c|}{$\begin{array}{l}\text { Total Empathy } \\
\text { (TE) }\end{array}$}} & \multirow{3}{*}{$\begin{array}{r}\underline{\mathrm{TE}} \\
\text { Rank } \\
\end{array}$} & \multirow{3}{*}{$\begin{array}{l}\underline{\mathrm{TE}} \\
\underline{\alpha}\end{array}$} \\
\hline & & \multicolumn{2}{|c|}{ Concern (EC) } & & & & & & & & & & \\
\hline & & M & SD & & & M & SD & & & M & SD & & \\
\hline \multicolumn{14}{|l|}{ North America } \\
\hline Canada & 7308 & 3.68 & .80 & 12 & .84 & 3.63 & .75 & 15 & .81 & 3.66 & .67 & 12 & .87 \\
\hline Mexico & 181 & 3.67 & .86 & 15 & .83 & 3.63 & .72 & 17 & .78 & 3.65 & .67 & 14 & .84 \\
\hline Puerto Rico & 41 & 3.60 & .89 & 26 & .83 & 3.67 & .69 & 9 & .74 & 3.64 & .67 & 16 & .84 \\
\hline US & 77537 & 3.78 & .77 & 5 & .83 & 3.67 & .74 & 10 & .82 & 3.72 & .66 & 7 & .87 \\
\hline \multicolumn{14}{|l|}{ South America } \\
\hline Argentina & 141 & 3.46 & .81 & 46 & .82 & 3.45 & .74 & 49 & .76 & 3.46 & .63 & 48 & .82 \\
\hline Brazil & 227 & 3.46 & .80 & 47 & .80 & 3.43 & .80 & 52 & .78 & 3.44 & .68 & 51 & .84 \\
\hline Chile & 46 & 3.61 & .78 & 25 & .80 & 3.61 & .75 & 19 & .77 & 3.61 & .65 & 25 & .83 \\
\hline Colombia & 36 & 3.46 & .80 & 44 & .76 & 3.54 & .86 & 33 & .82 & 3.50 & .76 & 40 & .87 \\
\hline Ecuador & 39 & 4.12 & .50 & 1 & .63 & 3.82 & .63 & 2 & .69 & 3.97 & .52 & 1 & .80 \\
\hline
\end{tabular}




$\begin{array}{lllllllllllllll}\text { Peru } & 35 & 3.74 & 1.00 & 9 & .91 & 3.79 & .80 & 3 & .76 & 3.77 & .78 & 3 & .88 \\ \text { Venezuela } & 24 & 3.39 & .46 & 54 & .47 & 3.13 & .65 & 63 & .76 & 3.26 & .48 & 62 & .76\end{array}$

West Europe

\begin{tabular}{|c|c|c|c|c|c|c|c|c|c|c|c|c|c|}
\hline Austria & 244 & 3.58 & .78 & 29 & .83 & 3.59 & .73 & 25 & .77 & 3.58 & .65 & 27 & .85 \\
\hline Belgium & 459 & 3.54 & .73 & 38 & .80 & 3.52 & .74 & 37 & .79 & 3.53 & .63 & 36 & .84 \\
\hline Denmark & 749 & 3.78 & .78 & 6 & .82 & 3.74 & .72 & 4 & .79 & 3.76 & .65 & 4 & .86 \\
\hline Finland & 428 & 3.24 & .80 & 61 & .84 & 3.42 & .74 & 53 & .81 & 3.33 & .65 & 58 & .86 \\
\hline France & 818 & 3.60 & .76 & 27 & .81 & 3.50 & .76 & 41 & .79 & 3.55 & .65 & 31 & .85 \\
\hline Germany & 3614 & 3.62 & .70 & 20 & .77 & 3.60 & .71 & 20 & .78 & 3.61 & .61 & 22 & .84 \\
\hline Iceland & 52 & 3.30 & .72 & 59 & .75 & 3.60 & .73 & 22 & .78 & 3.45 & .57 & 50 & .78 \\
\hline Ireland & 328 & 3.56 & .80 & 35 & .82 & 3.49 & .76 & 44 & .79 & 3.52 & .67 & 38 & .85 \\
\hline Luxembourg & 37 & 3.56 & .73 & 36 & .84 & 3.70 & .65 & 7 & .78 & 3.63 & .56 & 18 & .83 \\
\hline Netherlands & 653 & 3.44 & .75 & 49 & .82 & 3.54 & .74 & 32 & .81 & 3.49 & .64 & 42 & .86 \\
\hline Norway & 524 & 3.42 & .83 & 50 & .85 & 3.53 & .79 & 36 & .83 & 3.47 & .72 & 44 & .88 \\
\hline Sweden & 766 & 3.40 & .84 & 52 & .85 & 3.49 & .77 & 42 & .80 & 3.45 & .70 & 49 & .87 \\
\hline Switzerland & 378 & 3.57 & .73 & 33 & .80 & 3.54 & .74 & 30 & .79 & 3.56 & .65 & 30 & .86 \\
\hline
\end{tabular}


UK

Eastern Europe

Czech Republic

Estonia

Hungary

Latvia

Lithuania

Poland

Romania

Serbia

Slovakia

Slovenia

South Europe

Bulgaria

Croatia

Greece

$\begin{array}{lll}2754 & 3.49 \quad .83\end{array}$

41

.84

3.44

.80

51

.82

3.47

.71

$47 \quad .88$ 


$\begin{array}{llllllllllrrrrrr}\text { Italy } & 208 & 3.66 & .68 & 18 & .74 & 3.59 & .70 & 27 & .76 & 3.62 & .57 & 20 & .80 \\ \text { Portugal } & 184 & 3.47 & .79 & 43 & .83 & 3.50 & .76 & 40 & .82 & 3.49 & .65 & 43 & .86 \\ \text { Spain } & 312 & 3.62 & .75 & 21 & .81 & 3.54 & .77 & 35 & .79 & 3.58 & .64 & 28 & .84\end{array}$

Middle East

$\begin{array}{lcccccccrrrrrrr}\text { Israel } & 97 & 3.66 & .79 & 17 & .81 & 3.62 & .83 & 18 & .86 & 3.64 & .68 & 15 & .86 \\ \text { Kuwait } & 22 & 3.69 & .55 & 11 & .75 & 3.66 & .76 & 11 & .85 & 3.68 & .57 & 10 & .86 \\ \text { Saudi Arabia } & 24 & 3.89 & .71 & 2 & .79 & 3.89 & .67 & 1 & .84 & 3.89 & .55 & 2 & .82 \\ \text { Turkey } & 41 & 3.63 & .88 & 19 & .87 & 3.59 & .74 & 24 & .80 & 3.61 & .70 & 23 & .88 \\ \text { United Arab Emirates } & 44 & 3.88 & .76 & 3 & .79 & 3.63 & .71 & 13 & .73 & 3.76 & .63 & 5 & .83\end{array}$

\section{Africa}

South Africa

$\begin{array}{lllll}176 & 3.42 & .87 & 51 & .86\end{array}$

$3.46 \quad .71$

48

.77

3.44

$.67 \quad 52 \quad .85$

Oceania

\section{Australia}

New Zealand

South/Southeast Asia

India
$2591 \quad 3.47 \quad .81$

$653 \quad 3.49 \quad .83$

42

.84

3.47

.80

$40 \quad .84$

3.49

.75

47

.83

43

.79

3.4

3.49

.68

$\begin{array}{ll}41 & .87\end{array}$

$\begin{array}{lll}229 & 3.62 \quad .76\end{array}$

$23 \quad .76$

3.45

.77

50

3.53

$.64 \quad 35$

.81 


$\begin{array}{lccccccccrrrrrrr}\text { Indonesia } & 31 & 3.61 & .73 & 24 & .78 & 3.63 & .85 & 16 & .85 & 3.62 & .70 & 21 & .87 \\ \text { Malaysia } & 81 & 3.72 & .75 & 10 & .83 & 3.59 & .71 & 26 & .77 & 3.66 & .62 & 11 & .84 \\ \text { Pakistan } & 22 & 3.78 & .78 & 7 & .80 & 3.31 & .72 & 60 & .62 & 3.55 & .55 & 32 & .69 \\ \text { Philippines } & 116 & 3.67 & .67 & 14 & .72 & 3.63 & .64 & 14 & .71 & 3.65 & .54 & 13 & .78 \\ \text { Singapore } & 151 & 3.58 & .70 & 31 & .80 & 3.51 & .59 & 38 & .78 & 3.54 & .58 & 33 & .83\end{array}$

\section{East Asia}

\begin{tabular}{|c|c|c|c|c|c|c|c|c|c|c|c|c|c|}
\hline China & 162 & 3.55 & .74 & 37 & .80 & 3.54 & .72 & 34 & .76 & 3.54 & .61 & 34 & .82 \\
\hline Hong Kong & 94 & 3.57 & .71 & 34 & .79 & 3.49 & .70 & 45 & .77 & 3.53 & .60 & 37 & .83 \\
\hline Japan & 332 & 3.58 & .76 & 30 & .81 & 3.60 & .76 & 23 & .81 & 3.59 & .66 & 26 & .86 \\
\hline Korea & 139 & 3.76 & .82 & 8 & .86 & 3.73 & .76 & 5 & .84 & 3.74 & .68 & 6 & .88 \\
\hline Russia & 59 & 3.34 & .94 & 55 & .87 & 3.54 & .84 & 31 & .83 & 3.44 & .79 & 53 & .89 \\
\hline Taiwan & 53 & 3.82 & .73 & 4 & .82 & 3.60 & .66 & 21 & .70 & 3.71 & .58 & 8 & .81 \\
\hline Thailand & 63 & 3.68 & .75 & 13 & .77 & 3.55 & .78 & 28 & .80 & 3.61 & .65 & 24 & .83 \\
\hline
\end{tabular}

\section{Central America}

\section{Costa Rica}

$\begin{array}{lll}30 & 3.66 \quad .70\end{array}$

$16 \quad .85$


effect size of the differences between countries. The magnitude of cross-country differences were small (Empathic Concern: $\eta^{2}{ }_{\mathrm{p}}$ $=.019$; Perspective Taking: $\eta^{2}=.008$; Total Empathy: $\left.\eta^{2}{ }_{\mathrm{p}}=.017\right)$. 
Supplementary Table 2

Empathy by Broader Geographic Region

\begin{tabular}{|c|c|c|c|c|c|c|c|}
\hline & Number & Empathic & Empathic & Perspective & Perspective & Total & Total \\
\hline & $\underline{\text { of }}$ & Concern & $\underline{\text { Concern }}$ & Taking & Taking & Empathy & Empathy \\
\hline & Countries & & $\underline{\text { Rank }}$ & & $\underline{\text { Rank }}$ & & $\underline{\text { Rank }}$ \\
\hline Cultural Regions & $\mathrm{n}$ & $\mathrm{M}$ & & $\mathrm{M}$ & & $\mathrm{M}$ & \\
\hline North America & 4 & 3.68 & 2 & 3.65 & 3 & 3.67 & 3 \\
\hline South America & 7 & 3.61 & 6 & 3.54 & 6 & 3.57 & 6 \\
\hline West Europe & 14 & 3.51 & 8 & 3.55 & 5 & 3.53 & 7 \\
\hline East Europe & 10 & 3.37 & 11 & 3.41 & 11 & 3.39 & 11 \\
\hline South Europe & 6 & 3.54 & 7 & 3.50 & 8 & 3.52 & 8 \\
\hline Middle East & 5 & 3.75 & 1 & 3.68 & 2 & 3.72 & 1 \\
\hline Africa & 1 & 3.42 & 10 & 3.46 & 10 & 3.44 & 10 \\
\hline Oceania & 2 & 3.48 & 9 & 3.48 & 9 & 3.48 & 9 \\
\hline South/Southeast Asia & 6 & 3.66 & 3 & 3.52 & 7 & 3.59 & 5 \\
\hline East Asia & 7 & 3.61 & 5 & 3.58 & 4 & 3.60 & 4 \\
\hline Central America & 1 & 3.66 & 4 & 3.71 & 1 & 3.69 & 2 \\
\hline
\end{tabular}

